\title{
Malignant Peritoneal Mesothelioma: Treatment Options and Survival
}

\author{
SILJA A.S. SALO ${ }^{1}$, ILKKA ILONEN ${ }^{2,3}$, SANNA LAAKSONEN ${ }^{2,4}$, MARJUKKA MYLLÄRNIEMI ${ }^{2,5}$, \\ JARMO A. SALO ${ }^{2,3}$ and TUOMO RANTANEN ${ }^{1,6}$ \\ ${ }^{1}$ Department of Surgery, Institute of Clinical Medicine, University of Eastern Finland, Kuopio, Finland; \\ ${ }^{2}$ Clinicum, Faculty of Medicine, University of Helsinki, Helsinki, Finland; \\ ${ }^{3}$ Department of General Thoracic and Esophageal Surgery, Heart and Lung Center, \\ Helsinki University Hospital and University of Helsinki, Helsinki, Finland; \\ ${ }^{4}$ Department of Pathology, University of Helsinki and HUSLAB, Helsinki University Hospital, Helsinki, Finland; \\ ${ }^{5}$ Department of Pulmonary Medicine, Heart and Lung Center, Helsinki University Hospital, Helsinki, Finland; \\ ${ }^{6}$ Department of Surgery, Kuopio University Hospital, Kuopio, Finland
}

\begin{abstract}
Background: Malignant peritoneal mesothelioma (MPeM) is a rare type of cancer with a poor prognosis. Cytoreductive surgery (CRS) with hyperthermic intraperitoneal chemotherapy (HIPEC) have been shown to improve survival. Treatment and survival of patients with MPeM have not been previously studied in Finland. Materials and Methods: The data consisted of all patients diagnosed with MPeM during years 2000-2012 in Finland, including cancer notifications, death certificates and information about asbestos exposure. Results: Among 50/94 (53.2\%) patients treated for MPeM, $44 / 50$ (88.0\%) were treated palliatively, $4 / 50$ (8.0\%) with radical surgery and chemotherapy, and 2/50 (4.0\%) with CRS plus HIPEC. Fiveyear survival was $50.0 \%$ for those treated with CRS plus HIPEC and $75.0 \%$ for those treated with radical surgery and chemotherapy. Radical surgery with chemotherapy was associated with significantly longer survival compared to radiation ( $p=0.008)$, chemotherapy and radiation ( $p=0.043)$, surgery, chemotherapy and radiation $(p=0.039)$, and palliative surgery $(p=0.009)$. Conclusion: Treatment of MPeM is heterogenic in Finland. CRS plus HIPEC, and radical surgery with chemotherapy seem to increase the survival. Patients considered candidates for radical surgery should be sent to specialized centers for further assessment.
\end{abstract}

Correspondence to: Professor Tuomo Rantanen, Department of Surgery, Kuopio University Hospital, Puijonlaaksontie 2, 70210 Kuopio, Finland. Tel: +358 17173311, e-mail: tuomo.rantanen@kuh.fi

Key Words: Mesothelioma, peritoneal mesothelioma, treatment, survival, Finland, CRS, HIPEC, chemotherapy, radiotherapy, asbestos exposure.
The annual incidence of malignant peritoneal mesothelioma (MPeM) has been reported to be 0.2 to 3 cases per $1,000,000$ people per year, globally (1). In our previous study, the incidence of MPeM was 0.74 cases per 1,000,000 people per year in Finland. The median survival time after diagnosis of MPeM in Finland was 4 months (2).

In the 1990s, cytoreduction combined with intraperitoneal chemotherapy was considered for patients with peritoneal mesothelioma (3). Since then, cytoreductive surgery (CRS) combined with hyperthermic intraperitoneal chemotherapy (HIPEC) is a treatment reported increasingly with promising long-term survival in highly selected patients (4). Implementing this treatment modality has improved the 5year survival rate to $50 \%$ in this patient group (5). Despite these advances in treatment, it has been noted that globally, the majority of patients with MPeM receive only palliative care or systemic chemotherapy (6), leaving many eligible patients without the benefit of this more invasive treatment modality. This phenomenon is noted in our previous study, in which the majority of patients were treated with palliative therapy or diagnosed during autopsy (2).

The primary aim of this study was to identify first-line treatments given to patients who were diagnosed with MPeM in Finland between the years 2000 and 2012 from medical records. We also assessed the effectiveness of the different treatment modalities given to these patients. The secondary aim was to clarify the effect of different treatment modalities on different histological subtypes and in patients exposed to asbestos.

\section{Materials and Methods}

This was a retrospective study involving all Finnish patients with MPeM diagnosed between 1st of January 2000 and 31st of December 2012. Basic information, means of diagnosis, distribution of the 
disease, histological subtypes and asbestos exposure of the patients were described earlier (2). In brief, data were collected from the Finnish Cancer Registry and Statistics Finland including cancer notifications and histological subtypes, death certificates and spreading of the disease. The patients' diagnostic procedures and treatment were identified from their medical records, which were obtained from all public hospitals with permission. Types of surgical procedures performed, different first-line chemotherapeutic agents used and total radiation doses given were clarified from the patients' medical records. Additionally, we checked patient survival collectively in May 2018 from the Population Register Center and Statistics Finland. Information about previous asbestos exposure and insurance decisions concerning occupational diseases was collected from the National Workers' Compensation Center. In addition, differences in survival according to histological subtype were studied.

A total of 94 patients were diagnosed with MPeM between 1st of January 2000 and 31st of December 2012. Forty patients (42.6\%) did not receive cancer-aimed treatment, and received only palliative or no treatment at all. These patients were excluded from this study since the aim of the study was to evaluate the efficacy of various given treatments. Four patients $(4.3 \%)$ were excluded from the study as they did not have primary MPeM: two with origin from tunica vaginalis testis, one from pleura, and one patient with peritoneal disseminated adenocarcinoma that was originally misdiagnosed as MPeM.

Statistical analysis. The data were collected, and analyzed using IBM SPSS Statistics version 24 for Mac (IBM, Armonk, NY, USA). Different treatment options were compared with each other by chisquare tests and with Fisher's exact test. Correlation was calculated by Pearson's correlation coefficient. Survival was calculated with Kaplan-Meier graphs. A $p$-value of less than 0.05 was regarded as significant.

Ethics. This study was approved by the Heart and Lung Center of Helsinki University Hospital, the National Institute of Health and Welfare, Statistics Finland, and as well by the Ethical Committee of Helsinki and Uusimaa Hospital District, approval numbers $\$ 31$, 22.03.2013; THL/989/5.05.00/2013; TK-53-862-13; 418/13/03/02/15, respectively.

\section{Results}

Altogether, 50 out of the 94 patients diagnosed with MPeM (53.2\%, male 33/60, female 17/34) received some kind of operative, chemotherapeutic or radiation treatment. Basic patient characteristics are presented in Table I.

There was no statistically significant association between sex and given treatment $(p=0.090)$, nor with survival $(p=0.402)$.

Treatment methods. First-line chemotherapy was the most used treatment modality. The chemotherapeutic agents used varied and are presented in Figure 1.

Other ways of treatment used were radiation only, surgery (radical, palliative, CRS plus HIPEC) and combinations of the above treatment methods (Table II). In radiation therapy, radiation doses used ranged between 12 and $30 \mathrm{~Gy}$.
Table I. Basic information of patients with malignant peritoneal mesothelioma.

\begin{tabular}{lrrr}
\hline Variable & Total & Male & Female \\
\hline Median age (years) & $61.5(24-88)$ & 61 & 64 \\
Disease extent, $\mathrm{n}$ & & & \\
Local & 2 & 2 & 0 \\
FRLN & 29 & 18 & 11 \\
DM & 1 & 1 & 0 \\
Unknown & 18 & 12 & 6 \\
Histological subtype, $\mathrm{n}$ & & & \\
Epithelial & 19 & 12 & 7 \\
Sarcomatoid & 2 & 2 & 0 \\
Biphasic & 4 & 3 & 1 \\
Unknown & 25 & 16 & 9 \\
Asbestos exposure, $\mathrm{n}$ & & & \\
Yes & 11 & 9 & 10 \\
No & 21 & 11 & 5 \\
Unknown & 18 & 13 & 17 \\
Diagnosis, $\mathrm{n}$ & & & 0 \\
PTH & 37 & 20 & 0 \\
MH & 4 & 4 & 0 \\
Obduction & 8 & 8 & \\
Clinical & 1 & & \\
Total & & & \\
\hline
\end{tabular}

FRLN: Further than regional lymph nodes; DM: distant metastasis; PTH: primary tumor histology; MH: metastatic histology.

Fifteen out of the 50 patients $(30.0 \%)$ had undergone surgery during their treatment. The number of radical operations including peritonectomy was six, of which two were with and four without HIPEC. Radical operations included radical cytoreductive resection of the tumor and peritonectomy. The number of palliative operations was nine, including resection of omentum, resection of resectable tumor during explorative laparotomy, Hartman operation, ileotransversostomy and abdominal hysterectomy with bilateral salpingo-ophorectomy. Among two of the patients treated with palliative surgery, chemotherapy and radiation were combined in the treatment.

In all of the radically operated cases, adjuvant systemic chemotherapy was given. Chemotherapeutic agents used were pemetrexed combined with carboplatin or with cisplatin. In CRS with HIPEC, after radical peritonectomy and macroscopically radical resection, HIPEC was performed with mitomycin or the combination of doxorubicin and cisplatin.

Survival. With a median survival of 62 months, radical surgery with chemotherapy was related to a longer survival, compared to radiation $(p=0.008)$, chemotherapy with radiation $(p=0.043)$, palliative surgery with chemotherapy and radiation $(p=0.039)$, and palliative surgery $(p=0.009)$. CRS with HIPEC, with a median survival of 40 months, was 
Table II. Different treatment options used in the treatment of patients with malignant peritoneal mesothelioma.

\begin{tabular}{|c|c|c|c|c|}
\hline Treatment & Patients, n (\%) & Male, $\mathrm{n}$ & Female, $\mathrm{n}$ & Median age (range) of diagnosis, years \\
\hline Ctx & $24 / 50(48.0 \%)$ & 13 & 11 & $61(53-75)$ \\
\hline Palliative surgery & $7 / 50(14.0 \%)$ & 6 & 1 & $67(55-81)$ \\
\hline CRT & $6 / 50(12.0 \%)$ & 6 & 0 & $55(37-74)$ \\
\hline RT & $5 / 50(10.0 \%)$ & 3 & 2 & $75(56-88)$ \\
\hline Radical surgery + Ctx & $4 / 50(8.0 \%)$ & 3 & 1 & $61(24-67)$ \\
\hline CRS + HIPEC & $2 / 50(4.0 \%)$ & 2 & 0 & $62(57-66)$ \\
\hline Palliative surgery + CRT & $2 / 50(4.0 \%)$ & 0 & 2 & $40(27-52)$ \\
\hline
\end{tabular}

Ctx: Chemotherapy; RT: radiotherapy; CRT: chemotherapy with radiotherapy.

not significantly associated with better survival compared to other treatments. Different treatment options are compared pairwise concerning survival in Table III. Median survival and survival percentages according to different treatment options after 1,3 and 6 months, and 1 and 5 years are presented in Table IV. Survival rates according to the use of different chemotherapeutic agents are presented in Figure 1.

Extent of disease. Proportions of different treatment options according to disease distribution are presented in Figure 2. Exact information about the level of disease spread was available for 32 out of the 50 patients $(64.4 \%)$. There was no significant association between survival and the level of spread.

Histology. Information on the histological subtype was available for 25 out of the 50 cases $(50.0 \%$ ), of which $19 / 25$ $(76.0 \%)$ were epithelial, 2/25 (8.0\%) sarcomatoid, and 4/25 $(16.0 \%)$ were biphasic type. Median survival time after diagnosis was nine (range=2-92) months in those with epithelial MPeM, 1 (range=1-8) month in those with sarcomatoid MPeM, and 2 (range 1-68) months in those with biphasic MPeM. The epithelial subtype was associated with better survival compared to the sarcomatoid subtype $(p=0.039)$. The proportions of treatments used according to histological subtype are presented in Figure 3. Extent of disease among different histological subtypes is presented in Figure 4.

Asbestos exposure. Information about whether there was previous exposure to asbestos was available for 32 out of the 50 patients $(64.0 \%)$, of whom $7 / 32$ (21.9\%) had a history of asbestos exposure. Median survival time after diagnosis of patients with asbestos exposure was 8 (range 2-58) months, while it was 40 (range 1-92) months for patients without exposure. Asbestos exposure was associated with worse survival $(p=0.025)$. Histological subtypes of patients exposed and not exposed to asbestos are presented in Figure 5.

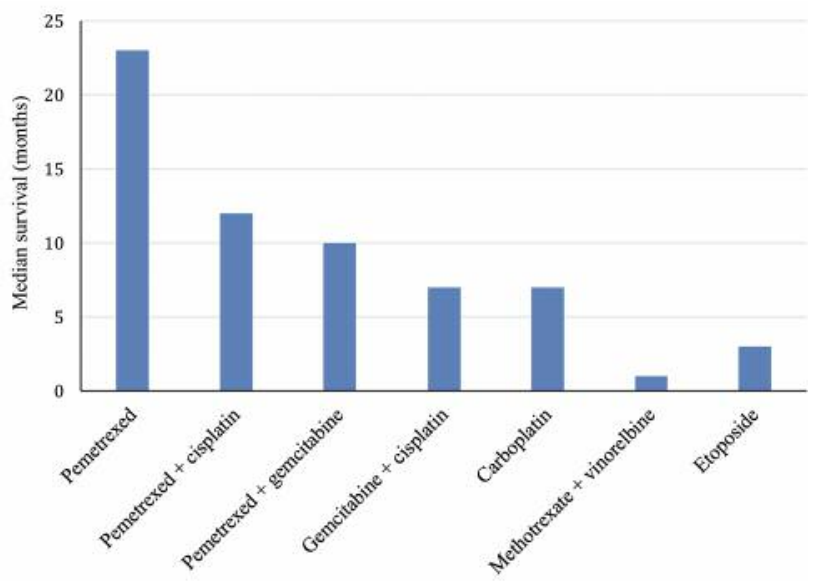

Figure 1. Different chemotherapeutic agents and their effect on survival.

\section{Discussion}

In our study, the treatment methods of MPeM were shown to be heterogenic and varied widely. The most prevalent treatment methods were chemotherapy and palliative surgery. Radical surgery with chemotherapy and CRS with HIPEC were associated with superior overall survival. To our laudable, treatment of MPeM and its effect on survival in Finland is reported here for the first time.

In our study, patients with radical surgery reached a 5-year survival of $50.0 \%$ with HIPEC and $75.0 \%$ without HIPEC. The survival rates of patients treated with CRS plus HIPEC are in accordance with earlier studies (7-12). An interesting observation was that survival results for patients not treated with HIPEC were even better than for those treated with HIPEC. The reason for this remains unclear since the distribution and histological subtypes did not differ for these patients. The small number of patients treated with CRS plus HIPEC in our study is due to the facts that HIPEC was not performed in Finland until 2007 and there was a small number of MPeM cases in Finland during the study period. 


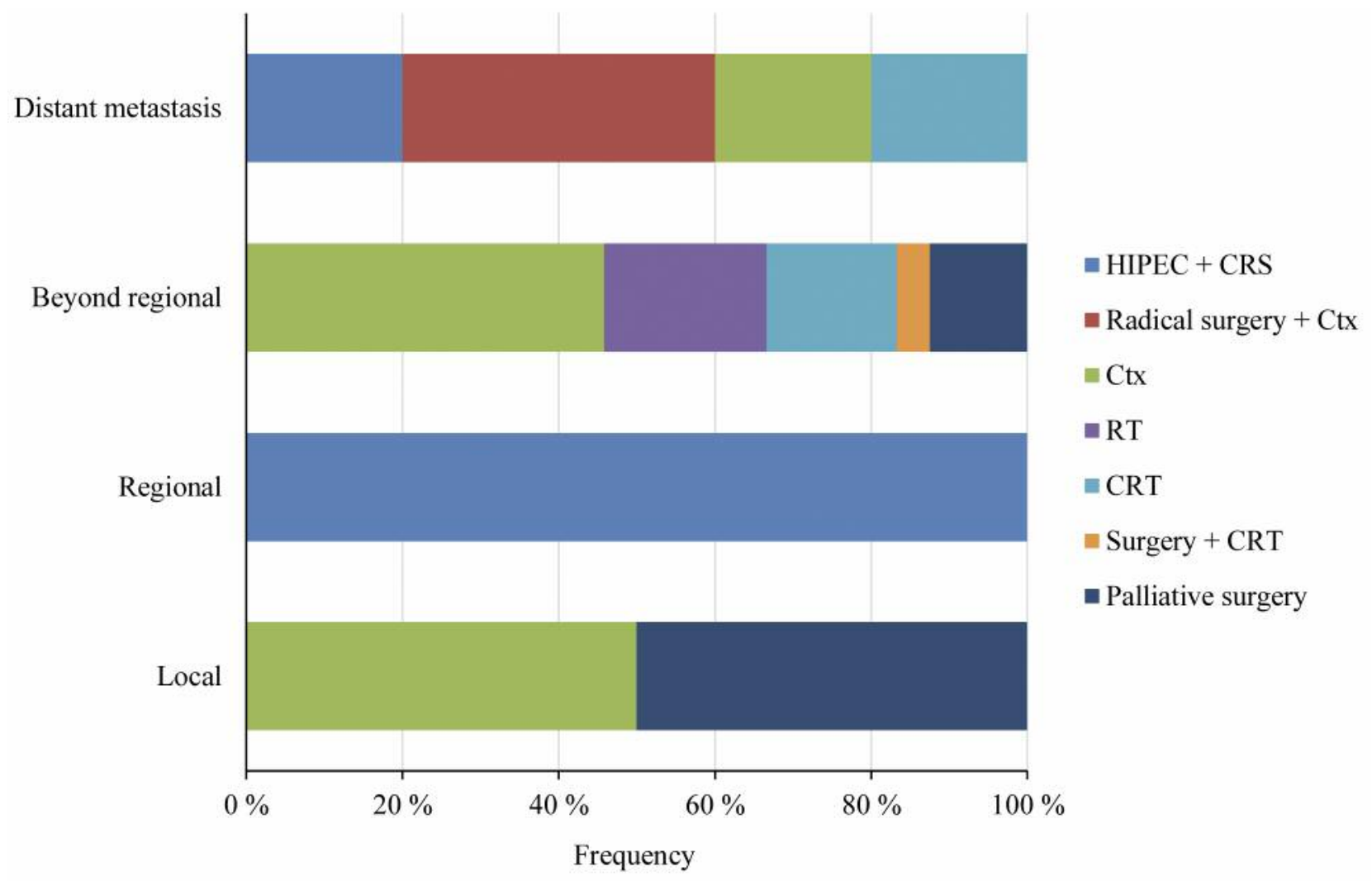

Figure 2. Disease extent and treatment methods used. Ctx: Chemotherapy; RT: radiotherapy; CRT: chemotherapy with radiotherapy.

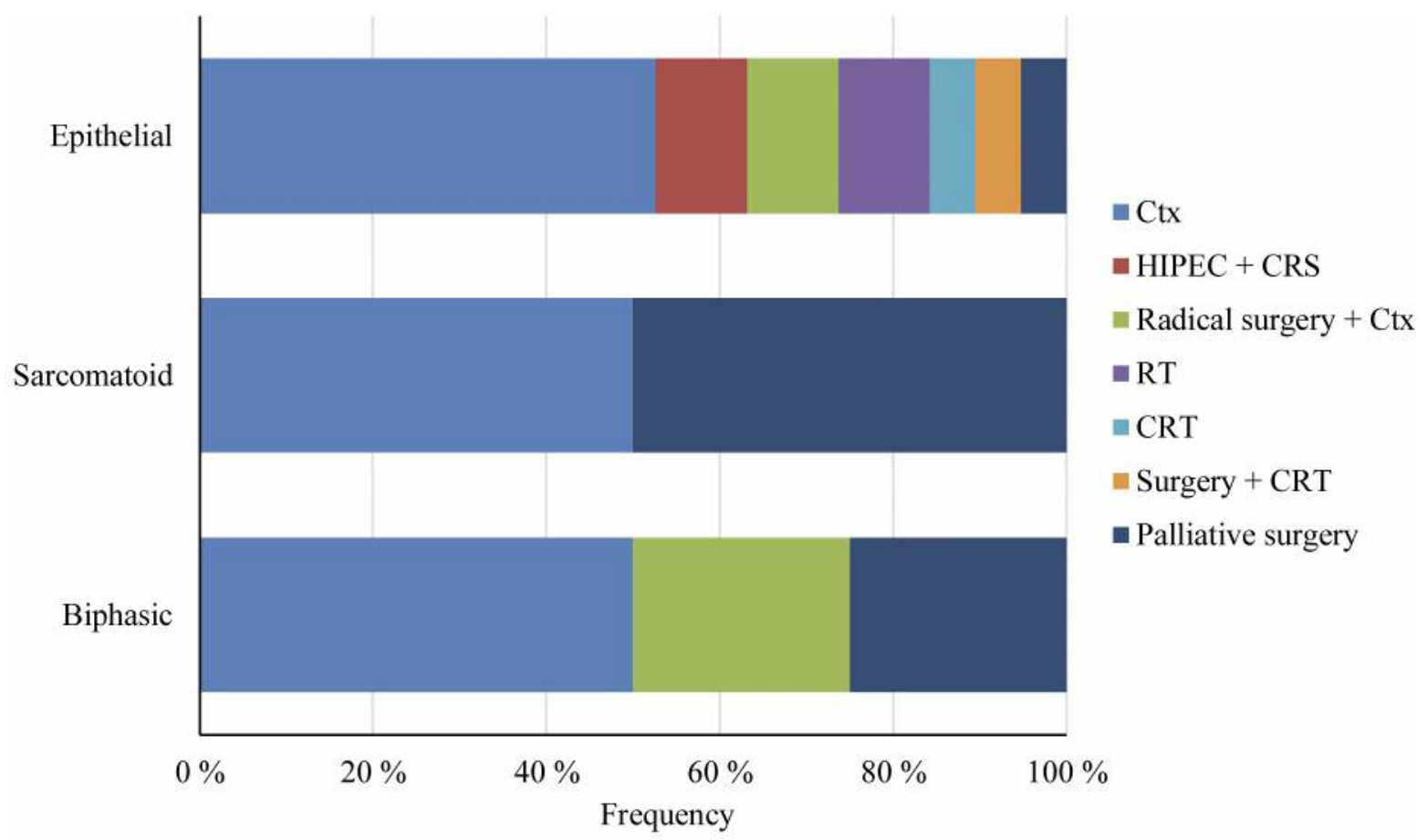

Figure 3. Proportions of used treatments on different histological subtypes of malignant peritoneal mesothelioma among patients. Ctx: Chemotherapy; RT: radiotherapy; CRT: chemotherapy with radiotherapy. 


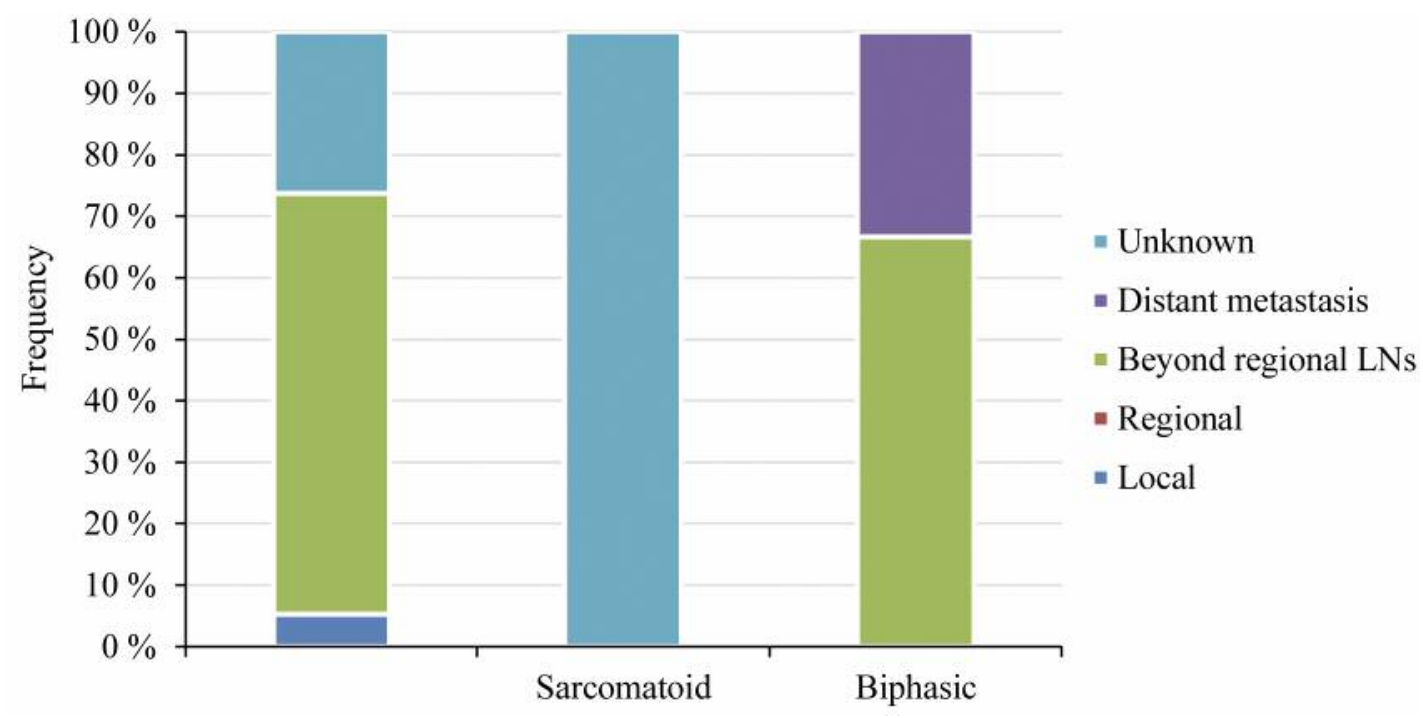

Figure 4. Levels of distribution among different histological subtypes of patients with malignant peritoneal mesothelioma. LNs: Lymph nodes.

In addition, the small number of cases in each patient group may cause statistical bias when comparing different treatment methods. Today, CRS combined with HIPEC is recommended as a first-line treatment for patients with an operable tumor and who can tolerate the planned procedure (13).

Systemic chemotherapy increased the 6-month survival to $79.2 \%$, but did not extend the long-term survival. Previous reports also stated that systemic chemotherapy was of palliative benefit, however, not improving survival (14). Systemic chemotherapy is considered as an alternative therapy for inoperable patients (15). Pemetrexed and the combination of pemetrexed and cisplatin led to the best prognoses, with median survival of 23 and 12 months, respectively. Similar results were found in earlier literature (16). Pemetrexed with cisplatin or carboplatin is considered as standard first-line systemic chemotherapy (15). In earlier studies, pemetrexed and gemcitabine were shown to increase survival, however, with a response rate not greater than $15 \%$ (17).

In the present study, radiation and palliative surgery were not associated with longer survival, as neither of these measures were aimed to reduce the overall tumor burden. Earlier literature states that the efficacy of radiation for MPeM is unclear (18). MPeM was shown to be resistant to radiation therapy alone, but radiation appeared to be more effective when combined with radical surgery and intraperitoneal chemotherapy $(19,20)$. In addition, unresectable MPeM can be treated with the combination of chemotherapy, radiotherapy and immunotherapy (21).

Epithelial MPeM was associated with the best survival among all histological subtypes, while sarcomatoid and biphasic MPeM had worse prognosis, with no significant

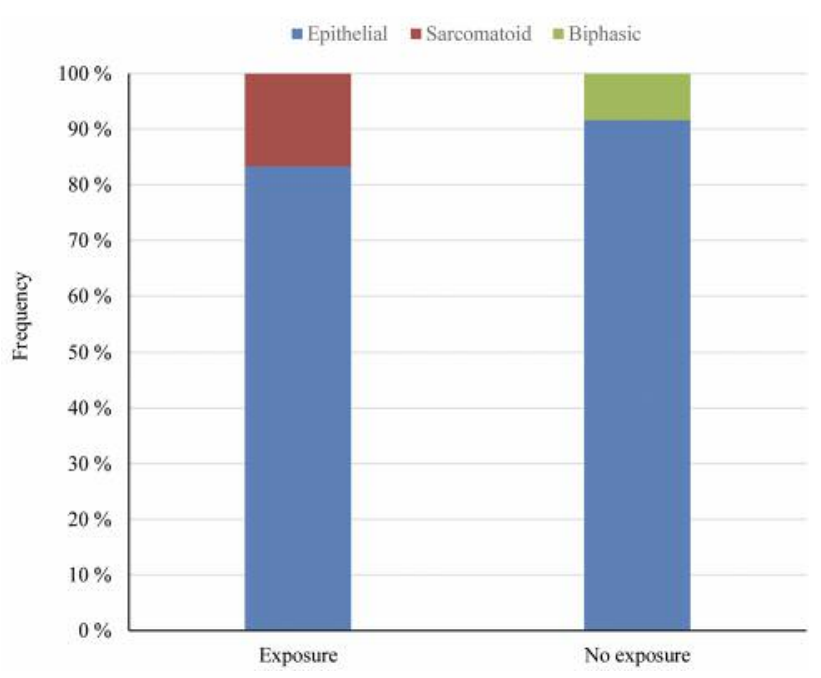

Figure 5. The histological subtypes of patients with malignant peritoneal mesothelioma with and without asbestos exposure.

difference in this study. However, the small number of patients with histological subtypes may have biased the results. In earlier literature, the epithelial subtype of MPeM was identified as a favorable prognostic factor $(18,22)$. None of the patients with sarcomatoid subtype were treated with radical surgery nor with CRS with HIPEC. In earlier literature, the sarcomatoid subtype was associated with worse prognosis (23). Magge et al. stated that aggressive histologies, such as sarcomatoid and biphasic subtypes may not benefit from CRS with HIPEC (24). 
Table III. Survival results after diagnosis compared pairwise with Fisher's exact test, endpoint 60 months. Significant p-values are shown in bold.

\begin{tabular}{lccccccc}
\hline Treatment & $\begin{array}{c}\text { HIPEC } \\
\text { +CRS }\end{array}$ & $\begin{array}{c}\text { Radical } \\
\text { surgery + Ctx }\end{array}$ & Ctx & RT & CRT & $\begin{array}{c}\text { Palliative } \\
\text { surgery + CRT }\end{array}$ & $\begin{array}{c}\text { Palliative } \\
\text { surgery }\end{array}$ \\
\hline HIPEC+CRS & & 0.083 & 0.683 & 0.090 & 0.758 & 0.225 & 0.112 \\
Radical surgery+Ctx & 0.083 & & 0.185 & $\mathbf{0 . 0 0 8}$ & $\mathbf{0 . 0 4 3}$ & $\mathbf{0 . 0 3 9}$ & $\mathbf{0 . 0 0 9}$ \\
Ctx & 0.683 & 0.185 & & $\mathbf{0 . 0 3 7}$ & 0.805 & 0.233 & 0.014 \\
Radiation & 0.090 & $\mathbf{0 . 0 0 8}$ & $\mathbf{0 . 0 3 7}$ & & 0.103 & 0.926 & 0.366 \\
CRT & 0.758 & $\mathbf{0 . 0 4 3}$ & 0.805 & 0.103 & & 0.034 \\
Palliative surgery+CRT & 0.225 & $\mathbf{0 . 0 3 9}$ & 0.233 & 0.926 & 0.366 & 0.838 \\
Palliative surgery & 0.112 & $\mathbf{0 . 0 0 9}$ & 0.014 & 0.968 & $\mathbf{0 . 0 3 4}$ & 0.838 & \\
\hline
\end{tabular}

Ctx: Chemotherapy; RT: radiotherapy; CRT: chemotherapy with radiotherapy.

Table IV. Median survival and survival percentages after diagnosis in patients with malignant peritoneal mesothelioma treated with different treatment options.

\begin{tabular}{|c|c|c|c|c|c|c|}
\hline \multirow[b]{2}{*}{ Treatment } & \multirow[b]{2}{*}{ Median survival (range), months } & \multicolumn{5}{|c|}{ Survival at $(\%)$} \\
\hline & & 1 Month & 3 Months & 6 Months & 1 Year & 5 Years \\
\hline HIPEC+CRS & $40(40-40)$ & $100 \%$ & $100 \%$ & $100 \%$ & $100 \%$ & $50.0 \%$ \\
\hline Radical surgery+Ctx & $62(57-68)$ & $100 \%$ & $100 \%$ & $100 \%$ & $100 \%$ & $75.0 \%$ \\
\hline $\mathrm{Ctx}$ & $9(0-92)$ & $95.8 \%$ & $87.5 \%$ & $79.2 \%$ & $45.3 \%$ & $20.8 \%$ \\
\hline RT & $2(2-15)$ & $100 \%$ & $20.0 \%$ & $20.0 \%$ & $20.0 \%$ & $0.0 \%$ \\
\hline CRT & $8(1-58)$ & $100 \%$ & $83.3 \%$ & $83.3 \%$ & $50.0 \%$ & $0.0 \%$ \\
\hline Surgery+RT & $2(2-9)$ & $100 \%$ & $50.0 \%$ & $50.0 \%$ & $0.0 \%$ & $0.0 \%$ \\
\hline Palliative surgery & $1(1-18)$ & $100 \%$ & $57.1 \%$ & $42.9 \%$ & $28.6 \%$ & $14.3 \%$ \\
\hline Total & $8(0-92)$ & $98.0 \%$ & $76.0 \%$ & $70.0 \%$ & $46.0 \%$ & $20.0 \%$ \\
\hline
\end{tabular}

Ctx: Chemotherapy; RT: radiotherapy; CRT: chemotherapy with radiotherapy.

The limitations of our studies are its retrospective setting and the relatively small number of patients. However, in previous publications, the treatment of MPeM has mostly been examined through retrospective, single-institutional studies (25). No randomized controlled trials have been published on treatment options for MPeM (25). Our study deals with the experience of the whole country and several institutions, which can be considered as a strength of our study.

\section{Conclusion}

In conclusion, MPeM is a rare disease and almost half the patients remain untreated. HIPEC with CRS and radical surgery with chemotherapy seem to increase the long-term survival. Treatment methods may be diverse due to the rarity of the disease and difficulties in diagnostics. Therefore, patients considered candidates for radical surgery should be sent to specialized centers for further assessment.

\section{Conflicts of Interest}

The Authors have no conflicts of interest to declare in regard to this study.

\section{Acknowledgements}

Silja Salo received a personal grant from the Finnish Cultural Foundation's North Savo Regional Fund. The study was supported by the Cancer Society of Finland and the Finnish Work Environment Fund.

\section{References}

1 Mirarabshahii P, Pillai K, Chua TC, Pourgholami MH and Morris DL: Diffuse malignant peritoneal mesothelioma-an update on treatment. Cancer Treat Rev 38: 605-612, 2012.

2 Salo SAS, Ilonen I, Laaksonen S, Myllarniemi M, Salo JA and Rantanen T: Epidemiology of malignant peritoneal mesothelioma: A population-based study. Cancer Epidemiol 51: 81-86, 2017.

3 Sugarbaker PH: Peritonectomy procedures. Ann Surg 221: 2942, 1995 . 
4 Alexander HR, Li CY and Kennedy TJ: Current management and future opportunities for peritoneal metastases: Peritoneal mesothelioma. Ann Surg Oncol 25: 2159-2164, 2018.

5 Yan TD, Deraco M, Baratti D, Kusamura S, Elias D, Glehen O, Gilly FN, Levine EA, Shen P, Mohamed F, Moran BJ, Morris DL, Chua TC, Piso P and Sugarbaker PH: Cytoreductive surgery and hyperthermic intraperitoneal chemotherapy for malignant peritoneal mesothelioma: Multi-institutional experience. J Clin Oncol 27: 6237-6242, 2009.

6 Sugarbaker PH: Update on the management of malignant peritoneal mesothelioma. Transl Lung Cancer Res 7: 599-608, 2018.

7 Helm JH, Miura JT, Glenn JA, Marcus RK, Larrieux G, Jayakrishnan TT, Donahue AE, Gamblin TC, Turaga KK and Johnston FM: Cytoreductive surgery and hyperthermic intraperitoneal chemotherapy for malignant peritoneal mesothelioma: A systematic review and meta-analysis. Ann Surg Oncol 22: 16861693, 2015.

8 Alexander HR, Bartlett DL, Pingpank JF, Libutti SK, Royal R, Hughes MS, Holtzman M, Hanna N, Turner K, Beresneva T and Zhu Y: Treatment factors associated with long-term survival after cytoreductive surgery and regional chemotherapy for patients with malignant peritoneal mesothelioma. Surgery 153: 779-786, 2013.

9 Deraco M, De Simone M, Rossi CR, Cavaliere F, Difilippo F, Scuderi S, Pilatti P and Kusamura S: An Italian multicentric phase II study on peritonectomy and intra peritoneal hyperthermic perfusion (IPHP) to treat patients with peritoneal mesothelioma. J Exp Clin Cancer Res 22: 41-45, 2003.

10 Baratti D, Kusamura S, Cabras AD, Bertulli R, Hutanu I and Deraco M: Diffuse malignant peritoneal mesothelioma: Longterm survival with complete cytoreductive surgery followed by hyperthermic intraperitoneal chemotherapy (HIPEC). Eur J Cancer 49: 3140-3148, 2013.

11 Schaub NP, Alimchandani M, Quezado M, Kalina P, Eberhardt JS, Hughes MS, Beresnev T, Hassan R, Bartlett DL, Libutti SK, Pingpank JF, Royal RE, Kammula US, Pandalai P, Phan GQ, Stojadinovic A, Rudloff U, Alexander HR and Avital I: A novel nomogram for peritoneal mesothelioma predicts survival. Ann Surg Oncol 20: 555-561, 2013.

12 Yan TD, Edwards G, Alderman R, Marquardt CE and Sugarbaker PH: Morbidity and mortality assessment of cytoreductive surgery and perioperative intraperitoneal chemotherapy for diffuse malignant peritoneal mesothelioma prospective study of 70 consecutive cases. Ann Surg Oncol 14: 515-525, 2007.

13 Haque M, Hameed N, Perry CT, Carter E and Mneimneh WS: Malignant peritoneal mesothelioma in the setting of a ventriculoperitoneal shunt: A novel clinical presentation. Clin Med Insights Oncol 12, 2018. doi:10.1177/1179554918779583.

14 Lainakis G, Zagouri F, Kastritis E, Sergentanis TN, Bozas G, Dimopoulos MA and Papadimitriou CA: Systemic chemotherapy with pemetrexed and cisplatin for malignant peritoneal mesothelioma: A single-institution experience. Tumori 97: 25$29,2011$.
15 Boussios S, Moschetta M, Karathanasi A, Tsiouris AK, Kanellos FS, Tatsi K, Katsanos KH and Christodoulou DK: Malignant peritoneal mesothelioma: Clinical aspects, and therapeutic perspectives. Ann Gastroenterol 31: 659-669, 2018.

16 Garcia-Carbonero R and Paz-Ares L: Systemic chemotherapy in the management of malignant peritoneal mesothelioma. Eur $\mathbf{J}$ Surg Oncol 32: 676-681, 2006.

17 Simon GR, Verschraegen CF, Janne PA, Langer CJ, Dowlati A, Gadgeel SM, Kelly K, Kalemkerian GP, Traynor AM, Peng G, Gill J, Obasaju CK and Kindler HL: Pemetrexed plus gemcitabine as first-line chemotherapy for patients with peritoneal mesothelioma: Final report of a phase II trial. J Clin Oncol 26: 3567-3572, 2008.

18 Munkholm-Larsen S, Cao CQ and Yan TD: Malignant peritoneal mesothelioma. World J Gastrointest Surg 1: 38-48, 2009.

19 Blackham AU and Levine EA: Cytoreductive surgery with hyperthermic intraperitoneal chemotherapy for malignant peritoneal mesothelioma. Eur J Clin Med Oncol 4: 25-32, 2012.

20 Hesdorffer ME, Chabot JA, Keohan ML, Fountain K, Talbot S, Gabay M, Valentin C, Lee SM and Taub RN: Combined resection, intraperitoneal chemotherapy, and whole abdominal radiation for the treatment of malignant peritoneal mesothelioma. Am J Clin Oncol 31: 49-54, 2008.

21 Cao S, Jin S, Cao J, Shen J, Hu J, Che D, Pan B, Zhang J, He $\mathrm{X}$, Ding D, Gu F and Yu Y: Advances in malignant peritoneal mesothelioma. Int J Colorectal Dis 30: 1-10, 2015.

22 Sugarbaker PH, Yan TD, Stuart OA and Yoo D: Comprehensive management of diffuse malignant peritoneal mesothelioma. Eur J Surg Oncol 32: 686-691, 2006.

23 Kim J, Bhagwandin S and Labow DM: Malignant peritoneal mesothelioma: A review. Ann Transl Med 5: 236, 2017.

24 Magge D, Zenati MS, Austin F, Mavanur A, Sathaiah M, Ramalingam L, Jones H, Zureikat AH, Holtzman M, Ahrendt S, Pingpank J, Zeh HJ, Bartlett DL and Choudry HA: Malignant peritoneal mesothelioma: prognostic factors and oncologic outcome analysis. Ann Surg Oncol 21: 1159-1165, 2014.

25 Boffetta P: Epidemiology of peritoneal mesothelioma: a review. Ann Oncol 18: 985-990, 2007.
Received December 11, 2018

Revised December 19, 2018

Accepted December 21, 2018 